Original article

\title{
Relationship of quality of sleep with cognitive performance and emotional maturity among adolescents
}

\author{
Vizayieno Casavi ${ }^{\mathrm{a}}$, Sukesh Shetty ${ }^{\mathrm{a}}$, Jeevitha Alva ${ }^{\mathrm{b}}$, M. Nalini ${ }^{\mathrm{a}, *}$ \\ ${ }^{a}$ Department of Mental Health (Psychiatric) Nursing, Nitte Usha Institute of Nursing Sciences, Nitte (Deemed to be University), Deralakatate, Mangaluru, India \\ ${ }^{\mathrm{b}}$ Department of Paediatric Nursing Nitte Usha Institute of Nursing Sciences, Nitte (Deemed to be University), Deralakatate, Mangaluru, India
}

\section{A R T I C L E I N F O}

\section{Keywords:}

Adolescents

Cognition

Emotions

Insomnia

Sleep

\begin{abstract}
A B S T R A C T
Introduction: Sleep is a physiological behaviour typical in all animal species. Sound sleep nurtures the adolescent's health and emotions.

Objectives: This study objective was to find the relationship between sleep quality and cognitive performance and emotional maturity among adolescents in selected PU colleges.

Methods: Three hundred and twenty participants were selected by purposive sampling technique for the study. Socio-demographic data were collected, and sleep quality was assessed by Insomnia Severity Index (ISI) scale from all the 320 participants. The study participants who had scored poor sleep as per the ISI scale, i.e., the score between 8-21 were, further assessed for their cognitive and emotional maturity by Montreal Cognitive Assessment (MoCA) and Emotional Maturity Scale (EMS)

Results: Out of 320 participants,32 had subthreshold insomnia and clinical insomnia(moderate severity). These thirty-two subjects were categorized as poor sleep quality. Out of thirty-two subjects, the majority of those participants, 29 (90.6\%), had below normal cognitive performance. A negligible correlation $(r=0.205, p=0.261)$ was found between sleep quality and cognitive performance but not statistically significant. However, out of thirty-two participants, the majority of the participants (62.5\%) exhibited an above-average emotional maturity. Hence, a negligible correlation $(r=0.304, \mathrm{p}=0.091)$ between Quality of Sleep and Emotional Maturity was found but not statistically significant.

Conclusion: Adolescence requires enough sleep to maintain optimal health and wellbeing. A person with chronic sleep-deprivation can have fatigue, daytime sleepiness, clumsiness, and weight loss or weight gain. Sleep deprivation has influenced the cognitive and emotional performance of the adolescence.
\end{abstract}

\section{Introduction}

Sleep is the most significant factor for keeping the adolescents healthy and active. Adolescents need $8-10 \mathrm{~h}$ of sleep every night. ${ }^{1}$ However, most adolescents only get about 6.5-7.5 h of sleep per night or less than that. ${ }^{1}$ Sleep deprivation can dramatically affect adolescents lives, impacting their psychological wellness. ${ }^{2}$ It increases their risk of depression, anxiety, and low self-esteem. ${ }^{2}$ It can also affect academic performance at school. ${ }^{2}$ Sleep is essential during adolescents for mental, physical, social, and emotional development. ${ }^{3}$ Sleep deprivation may cause impairment in cognition and emotions among adolescents. ${ }^{4}$ Studies have revealed that short sleep duration negatively affects adolescents emotional development and reduces attention.,

Sleep is necessary to stay alert, boost memory, fight infection, be active and replenish the body. ${ }^{7}$ Sound sleep nurtures the adolescent's health and emotions. ${ }^{8}$ Quality sleep also influences the social acceptance of adolescents. ${ }^{8}$ Adolescents who fail to sleep at night will experience sleep during daytime. Increase daytime sleep results in automobile or work accidents and leads to other consequences also. ${ }^{8-10}$ Sleep deprivation causes poor school performance, heightened risk of drug and alcohol use, increased irritability, and aggressive behavior, all of which can interfere with relationships with peers, parents, and teachers. ${ }^{8}$ Sleep patterns tended to delay with increasing age, restricting night sleep. ${ }^{9}$ The onset of adolescence is also a time of both physiological and social changes that affect sleep. ${ }^{4}$

A study conducted in Germany among adolescents found that the average sleep duration on weekdays was $8.04 \pm 0.89 \mathrm{~h}$ and $9.51 \pm 1.65 \mathrm{~h}$ on weekends, respectively. ${ }^{11,12}$ Another cross-sectional study conducted

\footnotetext{
* Corresponding author. Tel.: +918095679510.

E-mail addresses: ayiecasavi@yahoo.in (V. Casavi), sukeshm@nitte.edu.in (S. Shetty), jeevithaalva@nitte.edu.in (J. Alva), nalini@nitte.edu.in (M. Nalini).
} 
in Europe among adolescents reported that the number of hours of sleep per night during school days was $7.7 \mathrm{~h} .{ }^{13}$ Sleep is inadequate not only in other parts of the world but also in Indian adolescents. A cross-sectional study on adolescent children in Kerala highlighted that sleep duration was inadequate in $60 \%$ of the children. ${ }^{14}$ Another cross-sectional survey conducted among school-going adolescents in Tamil Nadu found that over $64 \%$ of adolescents sleep $<8 \mathrm{~h}$ at night. ${ }^{15}$ Further, a cross-sectional study was conducted on adolescents in Karnataka in which $53.33 \%$ showed high sleep disturbances, whereas $46.67 \%$ showed fewer sleep disturbances. The study findings showed a positive correlation $(\mathrm{r}=$ 0.8921 ) between excessive smartphone use and sleep disturbances among adolescents. ${ }^{16}$ In addition, another cross-sectional survey conducted among adolescents in Udupi, Karnataka, found a 40\% prevalence rate of insomnia among adolescents. ${ }^{17}$

Sleep research suggests that adolescents need between 8 and $10 \mathrm{~h}$ of sleep every night, more than the required sleep hours of a child or an adult. ${ }^{14}$ However, most adolescents only get lesser than required amounts of sleep at night ${ }^{14} \mathrm{WHO}(2019)$ reported that $16 \%$ of the global mental health disease and injury burden accounts for adolescents between 10 and 19 years. ${ }^{18}$ The leading cause of disease worldwide is depression. ${ }^{30,31}$ It makes disability among adolescents inadequate sleep pattern influences the adolescent's mood and cognitive performance. ${ }^{19}$

Easy availability of mobile phones and other electronic gadgets made easy access for every individual. Nowadays, we are moving towards the nuclear family system, and most of the families both parents are employed, the adolescence left alone. The feeling of loneliness and inadequate monitoring make the adolescents spend much time on mobile phones during night hours. Hence the present study aimed to find the relationship between sleep quality with cognitive performance and emotional maturity among adolescents.

It is evident from the existing studies that adolescents are not getting enough sleep at night as recommended for their age group, which can negatively impact both their physical and mental health. Hence, the present study aimed to find the relationship between sleep quality with cognitive performance and emotional maturity among adolescents.

\section{Methods}

The research approach was a Quantitative approach, and the research design was cross-sectional design. Before the commencement of the study, all ethical guidelines were followed as per Nitte (Deemed to be University) policy.(IEC reference number: NUINS/CON/NU/IEC/ 2020-21/1829). The permission was taken from college authorities, assent was taken from student participants, and informed consent was obtained from the parents of student participants. Non-probability purposive sampling technique was used to select the study participants. The sample size was calculated using estimating single proportion formula. The study consisted of 320 Pre-University (PU) adolescents from selected Pre-University College, Nanthoor, Mangaluru. The data were collected from $25 / 01 / 2021$ to $04 / 11 / 2021$ in their respective institutions. The tools were self-administered to the participants. The mean age of the study participants was 16.49 years, and it ranged from 16 to 18 years. The adolescents who have diagnosed with any type of acute or chronic medical illnesses and on treatment were excluded from the study. The choice to participate in the study was voluntary.

The adolescence who have scored 8 and above in Insomnia Severity Index (ISI) scale were further assessed for Emotional maturity and cognitive performance.

\section{Data collection tool}

Socio-demographic data like age, gender, area of residence, educational level were collected from all the study participants. Insomnia Severity Index (ISI) was used to assess the quality of sleep for all 320 participants. The tool was designed by Prof Charles Morin and distributed by Mapi Research Trust on behalf of Prof Charles Morin, the copyright holder. It has seven questions designed as a brief screening tool for Insomnia. ${ }^{20,21}$ Based on the ISI score, the sleep quality is categorized as 0-7- No clinically significant insomnia,8-14- Subthreshold Insomnia, 15-21- Clinical Insomnia (moderate severity Insomnia), and 22-28 - Clinical Insomnia (severe). ${ }^{20,21}$

Montreal Cognitive Assessment (MoCA) and Emotional Maturity Scale (EMS) were administered to the participants who scored between 8 and 28 on the ISI score to assess their cognitive and emotional maturity level. ${ }^{22,23}$

The MoCA test is a one-page 30-point test administered approximately $10 \mathrm{~min}$. It is used to great lengths as a screening assessment for detecting cognitive impairment. The scores on MoCA range between 0 and 30 . A score of 26 or above is regarded as normal. The MoCA assesses several cognitive domains including Visuospatial and executive abilities, naming, memory, attention, language, abstraction, delayed recall, and orientation. The principal investigator has trained and obtained certificate from clinical psychologist before administering the tool to the study participants.

EMS was developed and standardized by Dr. Yashvir Singh and Dr. Mahesh Bhargava (1990). It is a self-reporting five-point scale. The test consists of 48 statements, each having five alternative responses, namely, "very much," "much," "undecided," "probably," and "never." T Higher the score on the EMS scale, the greater the degree of emotional immaturity and vice versa. The tool was purchased from National Psychological Corporation, Agra, for use. ${ }^{23}$

The principal investigator has obtained permission from all the authors of the tools to use for the present study.

\section{Statistical analysis}

The statistical analysis was done using the Statistical Package for the Social Sciences (SPSS-version 25). The demographic characteristics of the study were analyzed using frequency and percentage. The relationship between Quality of Sleep and Cognitive Performance and emotional maturity was analyzed using Spearman's Rank Correlation Coefficient. The association between Quality of Sleep with socio-demographic characteristics was analyzed using Fisher's exact test. The p-value less than 0.05 was considered significant.

\section{Results}

\subsection{Socio-demographic characteristics}

Table 1 shows the Frequency and Percentage of Socio-demographic Characteristics of the participants. Among the 320 participants, most were males $(56.9 \%)$ and 16 years of age $(58.8 \%)$. Most of them were from urban areas $(68.1 \%)$ and belonged to a nuclear family system (64.1\%). A higher percentage of the participants (51.2\%) spend 5-8 h on electronic gadgets, and $60 \%$ use the gadgets for academic purposes.

\subsection{Assessment of quality of sleep}

Table 2 depicts that the majority (90\%) of the participants experienced no clinically significant insomnia, whereas $8.4 \%$ of the participants showed subthreshold insomnia, and $1.6 \%$ had exhibited clinical insomnia (moderate severity).

\subsection{Relationship between Quality of Sleep and Cognitive Performance}

Table 3 depicts that out of thirty-two participants who were in the category of subthreshold Insomnia $(\mathrm{n}=24)$ and clinical Insomnia $(\mathrm{n}=$ 5) $90.6 \%$ exhibited below normal cognitive scores i.e., $>26$ and $(n=3)$ $9.4 \%$ were in normal cognitive score $(\geq 26)$ on the MoCA scale. 
Table 1

Frequency and percentage of socio-demographic characteristics $(n=320)$.

\begin{tabular}{llll}
\hline Socio-demographic characteristics $(\mathrm{n}=320)$ & $\begin{array}{l}\text { Frequency } \\
(\mathrm{f})\end{array}$ & $\begin{array}{l}\text { Percentage } \\
(\%)\end{array}$ \\
\hline Age & 16 & 188 & 58.8 \\
& 17 & 106 & 33.1 \\
Gender & 18 & 26 & 8.1 \\
& Male & 182 & 56.9 \\
Area of Residence & Female & 138 & 43.1 \\
& Rural & 102 & 31.9 \\
Type of Family & Urban & 218 & 68.1 \\
& Nuclear & 205 & 64.1 \\
Educational Level & Joint & 115 & 36 \\
Stream of studying & Class 11 & 227 & 70.9 \\
& Class 12 & 93 & 29.1 \\
Hours of sleep per night & Science & 170 & 53.1 \\
& Commerce & 150 & 46.9 \\
Do you have any accounts on social & $<7$ & 197 & 61.6 \\
media? & $7-8$ & 101 & 31.6 \\
The number of hours spent on & Yes & 22 & 6.9 \\
smartphones, TV, laptops, other & No & 291 & 90.9 \\
electronic gadgets. & 5-8 & 29 & 9.1 \\
Are you spending more time on & Academic & 196 & 48.8 \\
electronic devices for academic & purposes & & 51.2 \\
purposes or social media? & Social Media & 128 & 60 \\
\hline & & & 40 \\
\hline
\end{tabular}

Table 2

Frequency and Percentage on Quality of Sleep among adolescents $(n=320)$.

\begin{tabular}{lll}
\hline Quality of Sleep (ISI) $(\mathrm{n}=320)$ & Frequency & Percentage \\
\hline No clinically significant insomnia (0-7) $_{\text {Subthreshold Insomnia }}^{8-14}$ & 288 & 90 \\
Clinical Insomnia (moderate severity) $^{15-21}$ & 27 & 8.4 \\
Clinical Insomnia (severe) $^{22-28}$ & 5 & 1.6 \\
\hline
\end{tabular}

Table 3

Distribution of Frequency and Percentage of Cognitive Performance among adolescents $(\mathrm{n}=32)$.

\begin{tabular}{llll}
\hline $\begin{array}{l}\text { Cognitive } \\
\text { Performance (MoCA }\end{array}$ & ISI Score & Percentage \\
\cline { 2 - 3 } score) & $\begin{array}{l}\text { 8-14 (Subthreshold } \\
\text { Insomnia) }\end{array}$ & $\begin{array}{l}\text { 15-21 (Clinical } \\
\text { Insomnia-moderate } \\
\text { severity) }\end{array}$ & \\
\hline Below Normal $<\mathbf{2 6}$ & 24 & 5 & 90.6 \\
Normal $\geq \mathbf{2 6}$ & 3 & 0 & 9.4 \\
\hline
\end{tabular}

\subsection{Relationship between quality of sleep and emotional maturity}

Table 4 depicts that the majority of the participants (62.5\%) exhibited an above-average of Emotional Maturity (Fig. 1).

Table 5 shows that the majority of the participants exhibited an average level of Emotional Stability (40.6\%), Social Adjustment (46.9\%), Personality Integration (50\%), Independence (65.6\%), and an above-average level of Emotional progression (59.4\%) (Fig. 2).

Table 4

Distribution of Frequency and Percentage of Emotional Maturity of adolescents $(\mathrm{n}=32)$.

\begin{tabular}{lllll}
\hline & Below Average & Average & Above Average & High \\
\hline \multirow{2}{*}{ Emotional Maturity } & $\mathrm{f}(\%)$ & $\mathrm{f}(\%)$ & $\mathrm{f}(\%)$ & $\mathrm{f}(\%)$ \\
& $0(0 \%)$ & $9(28.1 \%)$ & $20(62.5 \%)$ & $3(9.4 \%)$ \\
\hline
\end{tabular}

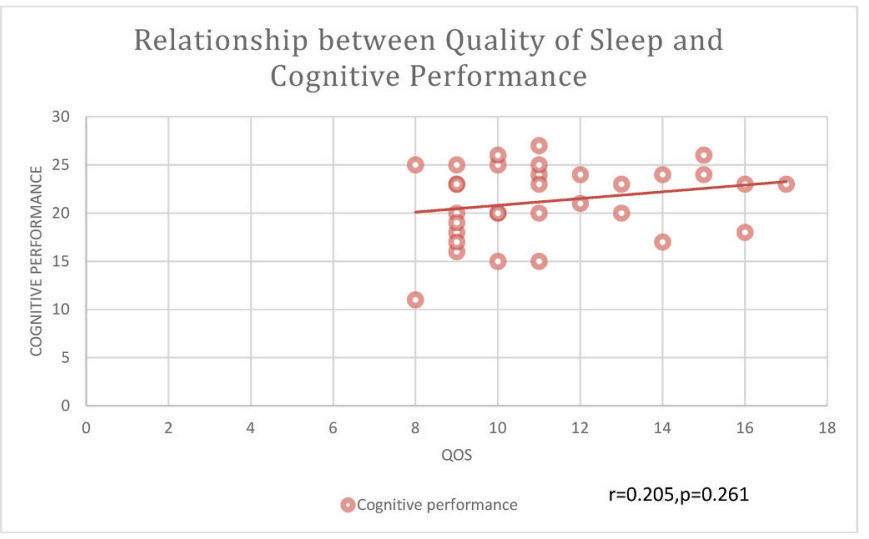

Fig. 1. Scattered diagram depicting the relationship between Quality of Sleep and Cognitive Performance.

Table 5

Domain-wise distribution of Frequency and Percentage of Emotional Maturity among adolescents $(\mathrm{n}=32)$.

\begin{tabular}{|c|c|c|c|c|}
\hline \multirow[t]{2}{*}{$\begin{array}{l}\text { Emotional Maturity (n } \\
=32 \text { ) }\end{array}$} & $\begin{array}{l}\text { Below } \\
\text { Average }\end{array}$ & Average & $\begin{array}{l}\text { Above } \\
\text { Average }\end{array}$ & High \\
\hline & $\mathrm{f}(\%)$ & $\mathrm{f}(\%)$ & $\mathrm{f}(\%)$ & $\mathrm{f}(\%)$ \\
\hline Emotional Stability & $0(0 \%)$ & $\begin{array}{l}13 \\
(40.6 \%)\end{array}$ & $10(31.3 \%)$ & $\begin{array}{l}9 \\
(28.1 \%)\end{array}$ \\
\hline Emotional Progression & $0(0 \%)$ & $9(28.1 \%)$ & $19(59.4 \%)$ & $\begin{array}{l}4 \\
(12.5 \%)\end{array}$ \\
\hline Social Adjustment & $0(0 \%)$ & $\begin{array}{l}15 \\
(46.9 \%)\end{array}$ & $14(43.8 \%)$ & $3(9.4 \%)$ \\
\hline Personality Integration & $1(3.1 \%)$ & $16(50 \%)$ & $13(40.6 \%)$ & $2(6.3 \%)$ \\
\hline Independence & $0(0 \%)$ & $\begin{array}{l}21 \\
(65.6 \%)\end{array}$ & $11(34.4 \%)$ & $0(0 \%)$ \\
\hline
\end{tabular}

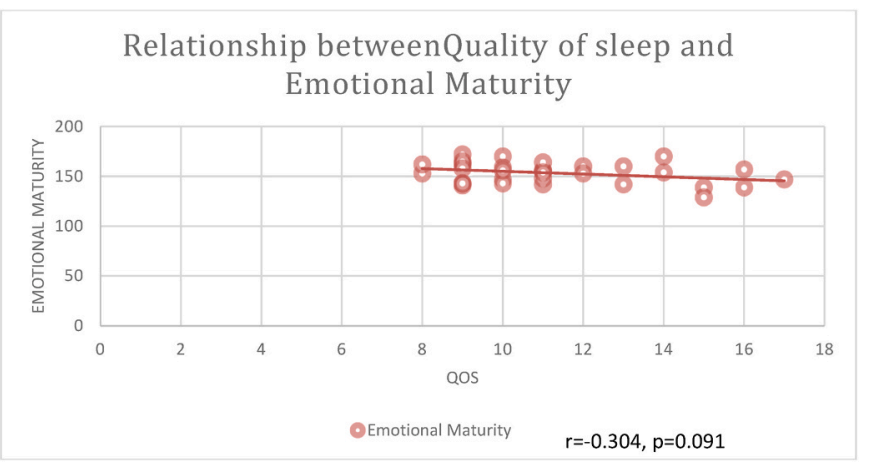

Fig. 2. Scattered diagram depicting the relationship of Quality of Sleep and Emotional Maturity.

\subsection{Association between quality of sleep with socio-demographic characteristics}

Table 6 shows that Fisher's exact test was used to find the association between quality of sleep and socio-demographic characteristics. The findings revealed that significant association between level of education, hours spent on electronic devices, and type of usage of devices with the severity of insomnia level as the p-value for these variables was less than 0.05 at a $5 \%$ significance level.

\section{Discussion}

In the present study, $90 \%$ of the participants experienced no clinically significant insomnia. This finding was a mismatch with the 
Table 6

Association between Quality of Sleep with socio-demographic characteristics.

\begin{tabular}{|c|c|c|c|c|c|c|}
\hline \multirow[t]{2}{*}{ Social Demographic characteristics } & & \multicolumn{3}{|l|}{ Insomnia Severity Level } & \multirow{2}{*}{$\begin{array}{l}\text { Fisher's } \\
\text { exact test }\end{array}$} & \multirow{2}{*}{$\begin{array}{l}\mathrm{p} \\
\text { value }\end{array}$} \\
\hline & & $\begin{array}{l}\text { No clinically significant } \\
\text { insomnia }(0-7)\end{array}$ & $\begin{array}{l}\text { Subthreshold } \\
\text { insomnia (8-14) }\end{array}$ & $\begin{array}{l}\text { Clinical insomnia } \\
\text { (moderate severity) (15-21 }\end{array}$ & & \\
\hline \multirow[t]{2}{*}{ Educational Level } & Class 11 & 213 & 11 & 3 & \multirow[t]{2}{*}{12.541} & \multirow[t]{2}{*}{0.001} \\
\hline & Class 12 & 75 & 16 & 2 & & \\
\hline \multirow[t]{2}{*}{ Number of hours spent on electronic devices } & $1-4 \mathrm{~h}$ & 152 & 4 & 0 & \multirow[t]{2}{*}{19.696} & \multirow[t]{2}{*}{0.001} \\
\hline & $5-8 \mathrm{~h}$ & 136 & 23 & 5 & & \\
\hline \multirow[t]{2}{*}{$\begin{array}{l}\text { Are you spending more time on electronic devices } \\
\text { for academic purposes or for social media }\end{array}$} & $\begin{array}{l}\text { Academic } \\
\text { purposes }\end{array}$ & 164 & 24 & 4 & \multirow[t]{2}{*}{12.162} & \multirow[t]{2}{*}{0.001} \\
\hline & Social Medi & 124 & 3 & 1 & & \\
\hline
\end{tabular}

research conducted by Karia SB et al. (2021), showed that $40 \%$ of science students and $33 \%$ of commerce students experienced no clinically significant insomnia, respectively. ${ }^{24}$ Another survey conducted by Karki $\mathrm{K}$ et al. (2021) highlighted that poor sleep quality was found among $31 \%{ }^{25} \mathrm{~A}$ dissimilar findings were reported by An J et al.(2014), that $26.7 \%$ of the adolescents had poor quality of sleep ${ }^{26}$ and Mercer PW et al. (1998), reported that $63 \%$ of the adolescents had poor sleep quality. ${ }^{25}$ These findings were discordant with the previous research because the present study data were collected right after the lockdown period. They had sufficient leisure time at home. In addition, the adolescents were exposed to electronic devices for academic purposes also. Though they had spent more time on electronic devices, they had restricted movement to outside and did not have clinical insomnia.

The current study shows that out of 320 participants, only thirty-two participants $(\mathrm{n}=32)$ were in the category of subthreshold insomnia $(\mathrm{n}=$ $27)$ and clinical insomnia $(n=5)$. In addition out of that $90.6 \%(n=29)$ of them shown below normal cognitive scores i.e. $\geq 26$ and $9.4 \%$ were in normal cognitive score $(n=3)(\geq 26)$ on the MoCA scale. A study conducted by Rossetti HC et al.(2015), showed that $66 \%$ of the participants had below normal cognitive level as fell below the suggested cut-off $(<26)$ on the MoCA scale. ${ }^{27,28}$ Aseem A et al. (2021), in their study, demonstrated a significant correlation between sleep quality and cognitive performance. ${ }^{29}$ While the present study indicated a weak positive correlation but no statistical significance for the correlation between sleep quality and cognitive performance. The pandemic situation also influenced this finding as adolescents could not move around and enjoy themselves with friends in the daytime. Adolescence with peer interaction can develop constructive interpersonal skills, autonomy, positive mental health, self-confidence, and satisfaction with social support. In addition, interaction with friends helps adolescence learn to make joint decisions, express empathy, and deepen their perspectives. ${ }^{32}$

The present study depicts a negligible correlation between the quality of sleep and emotional maturity, which contradicts a study done by Reddy R et al. (2017), where significant effects were observed for poor sleep quality with cognitive performance. ${ }^{31}$

The limitations of the study were that the study was conducted in only one school at Mangaluru. The data were collected from the study participants right after school reopened from Covid-19 lockdown, and the data collection period was constrained as theory classes were taken online. Future studies can be conducted for high school students also a similar study can be conducted for professional courses.

\section{Conclusion}

The present study showed that the quality of sleep in adolescents could be affected by the level of education, number of hours spent on electronic gadgets, and the type of usage of devices. Because the data was collected after lockdown and the adolescents were exposed to electronic devices for academic purposes, it is important to understand and limit spending unnecessary time on electronic devices as it can adversely affect sleep at night. Sleep deprivation, in turn, may affect cognitive performance and emotional maturity in adolescents. An adolescent should get the recommended hours of sleep every night for optimum functioning and overall health.

\section{Funding}

There as no funding for this study.

\section{Declaration of competing interest}

None declared.

\section{Acknowledgement}

The author would like to acknowledge the support of Dr. Naveen Shetty, Principal Dr. Nitte Shankara Adyanthaya Memorial PU College, Mangaluru, for willingly allowing her to conduct the study in his school.

\section{References}

1 Teens and sleep [internet] [Cited 2020 Sept 17]. Available from https://www.sleep foundation.org/articles/teens-and-sleep; 2020.

2 Teenagers and sleep [internet] [Cited 2020 Sept 17]. Available from https://www.be tterhealth.vic.gov.au/health/healthyliving/teenagers-and-sleep; 2020.

3 Tarokh L, Saletin JM, Carskadon MA. Sleep in adolescence: physiology, cognition, and mental health. Neurosci Biobehav Rev. 2016 Nov;70:182.

4 Sadeh A, Dahl RE, Shahar G, Rosenblat-Stein S. Sleep and the transition to adolescence: a longitudinal study. Sleep. 2009 Dec 1;32(12):1602-1609.

5 McMakin DL, Dahl RE, Buysse DJ, et al. The impact of experimental sleep restriction on affective functioning in social and nonsocial contexts among adolescents. JCPP ( $J$ Child Psychol Psychiatry). 2016 Sep;57(9):1027-1037.

6 Perez-Lloret S, Videla AJ, Richaudeau A, et al. A multi-step pathway connecting short sleep duration to daytime somnolence, reduced attention, and poor academic performance: an exploratory cross-sectional study in teenagers. J Clin Sleep Med. 2013 May 15;9(5):469-473.

7 Why is sleep so important? [Internet] [cited $2020 \mathrm{Jul}$ 6]. Available from: https:// www.unitypoint.org/livewell/article.aspx?id=b8411be0-64c3-455e-8dbf-751925 b41705; 2014.

8 Kelman BB. The sleep needs of adolescents. J Sch Nurs. 1999 Aug;15(3):14-19. the official publication of the National Association of School Nurses.

9 Gradisar M, Gardner G, Dohnt H. Recent worldwide sleep patterns and problems during adolescence: a review and meta-analysis of age, region, and sleep. Sleep Med. 2011 Feb 1;12(2):110-118.

10 Sadeh A, Dahl RE, Shahar G, Rosenblat-Stein S. Sleep and the transition to adolescence: a longitudinal study. Sleep. 2009 Dec 1;32(12):1602-1609.

11 Teenagers and sleep [internet] [cited 2020 Jul 6]. Available from http://www.bett erhealth.vic.gov.au/heath/healthyliving/teenagers-and-sleep; 2018.

12 Loessl B, Valerius G, Kopasz M, Hornyak M, Riemann D, Voderholzer U. Are adolescents chronically sleep-deprived? An investigation of sleep habits of adolescents in the Southwest of Germany. Child Care Health Dev. 2008 Sep;34(5): $549-556$.

13 Sarchiapone M, Mandelli L, Carli V, et al. Hours of sleep in adolescents and its association with anxiety, emotional concerns, and suicidal ideation. Sleep Med. 2014 Feb 1;15(2):248-254.

14 Mathew G, Varghese AD, Benjamin AI. A comparative study assessed sleep duration and associated factors among adolescents studying in different schools in an urban area of Kerala, India. Indian J Community Med. 2019 Oct;44(Suppl 1):S10. official publication of the Indian Association of Preventive and Social Medicine.

15 Murugesan G, Karthigeyan L, Selvagandhi PK, Gopichandran V. Sleep patterns, hygiene and daytime sleepiness among adolescent school-goers in three districts of Tamil Nadu: a descriptive study. Natl Med J India. 2018 Jul 1;31(4):196.

16 Youssouf S, Aribenchi SL, Salimath G. A cross-sectional study investigates the association between excessive smartphone use and sleep disturbances among adolescents, studying at KLE Society's Raja Lakhamagouda Science Institute, 
Belagavi, Karnataka, India, with a view to develop an information booklet. Indian $J$ Health Sci Biomed Res (KLEU). 2019 Sep 1;12(3):237.

17 Hebbar S, Jose TT, Nayak S. Prevalence and the contributing factors of insomnia among adolescents in selected secondary schools of Udupi district Karnataka. Manipal J Nurs Health Sci (MJNHS). 2017;3(1):23-28.

18 Adolescent mental health [Internet] [cited $2020 \mathrm{Jul} 6$ ]. Available from http://www. who.int/news-room/fact-sheets/detail/adolescent-mental-health; 2019.

19 Potkin KT, Bunney Jr WE. Sleep improves memory: the effect of sleep on long term memory in early adolescence. PLoS One. 2012 Aug 7;7(8), e42191.

20 Insomnia severity Index [internet] [cited 2020 Sept 17] Available from https:// www.serenitymedicalservices.com/wpcontent/uploads/2020/01/CEREVES_IS I-ENG.pdf; 2020.

21 Insomnia severity Index [internet] [cited 2020 Sept 17] Available from https://www.med.upenn.edu/cbti/assets/usercontent/documents/Insomnia\% 20Severity\%20Index\%20(ISI).pdf; 2020.

22 Montreal cognitive assessment (MoCA) [internet] [cited 2020 Sept 17] Available from https://www.mocatest.org/wp-content/uploads/2017/01/MoCA-New-Test-8. 1-2017-04.pdf; 2020.

23 Singh TK, Sharma A. Personality and emotional maturity of depressive and obsessive compulsive disorders. Int J Indian Psychol. 2014;1(4).

24 Rossetti HC, Lacritz LH, Cullum CM, Weiner MF. Normative data for the montreal cognitive assessment (MoCA) in a population-based sample. Neurology. 2011 Sep 27 77(13):1272-1275.
25 Karki K, Singh DR, Maharjan D, KC S, Shrestha S, Thapa DK. Internet addiction and sleep quality among adolescents in a peri-urban setting in Nepal: a cross-sectional school-based survey. PLoS One. 2021 Feb 18;16(2), e0246940.

26 An J, Sun Y, Wan Y, Chen J, Wang X, Tao F. Associations between problematic internet use and adolescents' physical and psychological symptoms: possible role of sleep quality. J Addiction Med. 2014 Jul 1;8(4):282-287.

27 Mercer PW, Merritt SL, Cowell JM. Differences in reported sleep need among adolescents. J Adolesc Health. 1998 Nov 1;23(5):259-263.

28 Bunker LN, Meena S. Feelings of social interaction anxiety and emotional maturity among Indian Adolescents in Relation to gender and caste. Int J Res Eng Appl Sci. 2015;5(7):134-142.

29 Aseem A, Bhati P, Chaudhry N, Hussain ME. Quality of sleep predicts prefrontal cognitive decline in Indian collegiates. Sleep Vigilance. 2021 Mar 16:1-8.

30 Arumugam B, Nagalingam S, Ganesan R. Electronic devices-the real ruler of the world. J Med Res Pract. 2014;3(2).

31 Reddy R, Palmer CA, Jackson C, Farris SG, Alfano CA. Impact of sleep restriction versus idealized sleep on emotional experience, reactivity and regulation in healthy adolescents. J Sleep Res. 2017 Aug;26(4):516-525.

32 Hair EC, Jager J, Garrett SB. Helping Teens Develop Healthy Social Skills and relationships:What the Research Shows about Navigating Adolescence. 